\title{
Analysis of the compressorless combined cycle gas turbine unit performance efficiency in district heating systems
}

\author{
Yuriy Borisov ${ }^{1,3}$, Nikolay Fominykh ${ }^{1}$, Eldar Ramazanov ${ }^{2}$ and Oleg Popel ${ }^{1}$ \\ ${ }^{1}$ Joint Institute for High Temperatures of the Russian Academy of Sciences, Izhorskaya St., Bldg. 13, Block 2, Moscow, Russia \\ ${ }^{2}$ Peoples' Friendship University of Russia (RUDN University), Miklukho-Maklaya str., Bldg. 6, Moscow, Russia \\ ${ }^{3}$ Bauman Moscow State Technical University, 2nd Baumanskaya St., Bldg. 5, Block 1, Moscow, Russia
}

\begin{abstract}
Nowadays, thermodynamic cycles are actively studied, in which pure oxygen and fuel are fed into a combustion chamber, and a temperature of a working fluid is regulated by the supply of carbon dioxide and/or water vapor. These cycles are called "oxygen-fuel". They allow easy to separate $\mathrm{CO} 2$, resulting from a fuel combustion, from the working fluid and remove it from the cycle in its pure form. In addition, it has already been shown that an efficiency of electric power generation of such cycles is approaching the best known technologies. However, the efficiency of cogeneration of electricity and heat is more important for many energy systems, especially for Russian, in comparison with the efficiency of electricity generation. The main goal of the study was to analyze the thermal efficiency for cogeneration of electricity and heat of one of the options for the implementation of oxygen-fuel cycles - compressorless combined cycle gas turbine (CCGT) units. A mathematical model of the compressorless CCGT units was developed, which allows to study the thermal performance in a wide range of operating modes. It is conventionally accepted that the system requires a maximum power for power supply of $300 \mathrm{MW}$, and a maximum power for heat supply of $600 \mathrm{MW}$. It is assumed that $300 \mathrm{MW}$ of electricity is constantly supplied to the network. In addition, the heat load is provided according to the standard schedule depending on the ambient temperature, and at the same time an averaged data on the temperature of atmospheric air for central Russia over a tenyear period is accepted. The comparison is made with a steam turbine CHP plant and a CCGTCHP plant. The results of the comparison showed a significant advantage of the compressorless CCGT unit.
\end{abstract}

\section{Introduction}

The desire to reduce anthropogenic emissions of greenhouse gases, including $\mathrm{CO} 2$, initiates the search for new technologies of generating electric and thermal energy. Recently, thermodynamic cycles, in which oxygen is extracted from the air before the combustion process, are actively studied [1-4]. Pure oxygen and fuel are supplied into the combustion chamber, and the temperature of the working fluid is regulated by the supply of carbon dioxide and/or water vapor. Thus, the spent working fluid consists of a mixture of carbon dioxide and water vapor. The phase transition temperatures of these components are very different that allow easy to separate such a mixture. Such cycles are called "oxygen-fuel". The compressorless CCGT units are one of the most promising options for the implementation of oxygen-fuel cycles for cogeneration of electric and thermal energy [5-7].
The main objective of the research was to study the parameters of the compressorless CCGT unit at various heat loads and to analyze the thermal efficiency of it in the district heating systems. 


\section{Description of a compressorless combined cycle gas turbine unit schematic}

A compressorless combined cycle gas turbine unit schematic is shown in Fig. 1. The pressure increase of the working fluid is carried out by the feed pumps of liquefied natural gas (LNG) 1, oxygen 2, carbon dioxide 3 and water 4 . The LNG pump controls the fuel supply. After the feed pump, LNG is sequentially fed to a cold utilizer of LNG 5 and a LNG heater 6, and then heated fuel enters a primary zone of a combustion chamber 7. The oxygen supply is regulated by the oxygen pump. After the oxygen pump, oxygen first enters an oxygen cold utilizer 8 , then into an oxygen heater 9. After which, the heated oxygen enters the primary zone of the combustion chamber.

The carbon dioxide pump controls the flow of $\mathrm{CO} 2$. After the carbon dioxide pump, $\mathrm{CO} 2$ first enters a heater 10, and then goes to a regenerative heat exchanger 11. Heated CO2 is supplied simultaneously to primary and secondary zones of the combustion chamber so as to ensure an acceptable quality of fuel combustion and the required temperature field at the combustion chamber outlet. A small fraction of $\mathrm{CO} 2$ is used to cool hot parts in a flow part of a combined cycle gas turbine 12 (not shown).

The feed water pump 4 supplies water to a recuperative heat exchanger 13 , and then, like $\mathrm{CO} 2$,
$\mathrm{H} 2 \mathrm{O}$ enters the primary and secondary zones. Thus, fuel is supplied to the combustion chamber in an amount that provides required thermal and electrical load. The oxygen supply is regulated so that the required combustion efficiency is provided by a minimum excess of oxygen. The supply of $\mathrm{CO} 2$ maintains the preset temperature of the working fluid in the turbine depending on the regulation law at the inlet or outlet. The supply of $\mathrm{H} 2 \mathrm{O}$ regulates the ratio of generating heat and electric energy.

The mixture of combustion products and recirculating $\mathrm{CO} 2$ and $\mathrm{H} 2 \mathrm{O}$ with the prescribed temperature, obtained in the combustion chamber, is the working fluid at the inlet of the combined cycle gas turbine 12. The working fluid expands in the turbine, doing work. The work, having performed in the combined cycle gas turbine, is converted into electricity by a generator 14 . The working fluid, spent in the turbine, is sent to recuperative heat exchangers 11 and 13, which heat up the recirculating $\mathrm{CO} 2$ and $\mathrm{H} 2 \mathrm{O}$. In recuperative heat exchangers, the working fluid is cooled to a temperature as close as possible to the dew temperature when the water vapor, included in the working fluid, begins to condense.

After the recuperative heat exchanger 11, the working fluid is directed to a low pressure contact condenser 15. It has two sections which locates one above the other. Water is supplied into a first section 16 with a temperature slightly higher than the

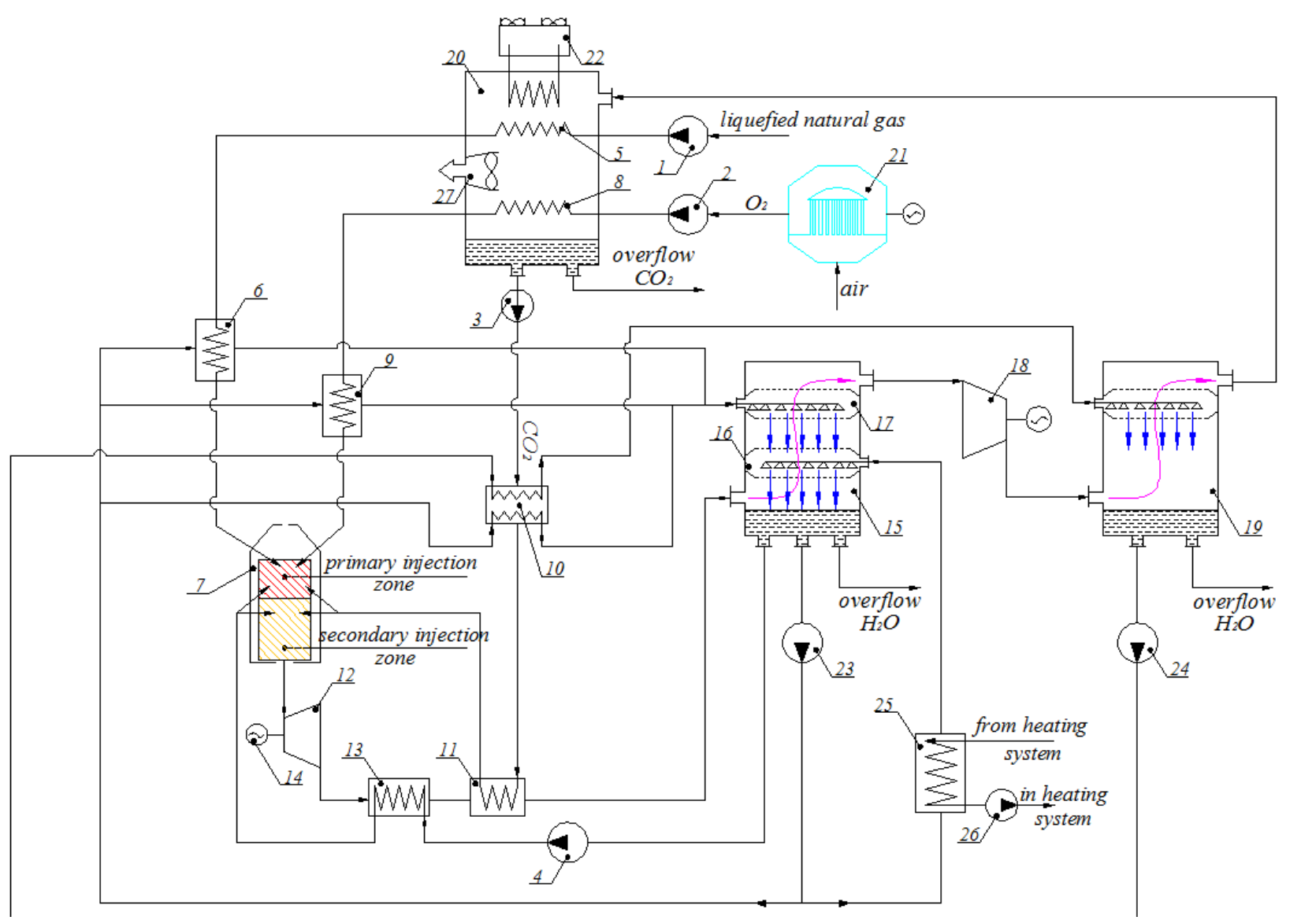

Fig. 1. Compressorless combined cycle gas turbine unit schematic. 
temperature of return network water for cooling the working fluid. Cooling water is supplied into a second section 17 with a temperature slightly higher than the temperature of liquid $\mathrm{CO} 2$. At the outlet of the low pressure contact condenser, the working fluid is carbon dioxide with small impurities, including a small amount of H2O. Therefore, in order to avoid freezing, the pressure of the working fluid is increased by a compressor of $\mathrm{CO} 218$ to $3,5 \mathrm{MPa}$ when the condensation temperature of $\mathrm{CO} 2$ is higher than the freezing temperature of $\mathrm{H} 2 \mathrm{O}$.

After that, the residual of $\mathrm{H} 2 \mathrm{O}$ is condensed in a high pressure contact condenser 19. The working fluid, having cooled in the contact condenser 19 , is sent to a liquefier of $\mathrm{CO} 2$ 20. Cold of oxygen from an air separation unit (ASU) 21 and LNG cold are used for the liquefaction of $\mathrm{CO} 2$. For this purpose, the liquefier of $\mathrm{CO} 2$ includes the liquid oxygen cold utilizer 8 and the LNG cold utilizer 5.

The entire shortage of cold, which is required to liquefy $\mathrm{CO} 2$, is compensated a refrigeration unit 22 . Each contact condenser has its own circulating water circuit. The circulation pumps 23 and 24 take in water from the contact condenser water tanks. Water is divided into several streams in the circulation circuit of the low pressure condenser after the circulation pump 23. Most of the water goes to a network water heater 25 after which it returns to the first section of the low pressure condenser. The remaining water is supplied in parallel streams to the fuel heater 6 , the oxygen heater 9 and the $\mathrm{CO} 2$ heater 10 .

Having released the heat in the heaters, the cooled water returns to the second section of the low pressure contact condenser. After the pump 24, the circulation water of the high pressure condenser is supplied to the $\mathrm{CO} 2$ heater 10 . It is designed so that two heating fluids are used for heating up. After the heater, this water returns to the high pressure contact condenser 19. The return network water is supplied to the network water heater 25. After that, water is heated to the temperature, required by the temperature graph, and returned to the heat network by a network water pump 26 .

Liquid oxygen is produced in the cryogenic ASU 21. The liquefier of CO2 20 is equipped with a system for removing non-condensable gases and collecting an excess of liquid $\mathrm{CO} 2$. In addition, the selection of excess $\mathrm{H} 2 \mathrm{O}$ is provided.

\section{Description of an adopted model of a district heating system}

It is assumed that a heat load is heating and a hot water supply. Thermal capacity of $600 \mathrm{MW}$ allows to provide heat to a residential area for 100-130 thousand people. It is accepted that the hot water supply capacity is $20 \%$ of the maximum heat output. The schedules of electric power requirement, being very diverse, and the issues of regulating the electric power of the energy system are beyond the scope of this work. Therefore, an option has been adopted in which the compressorless CCGT unit is not involved in the regulation of electric power.
Also, it is supposed that a power grid is large enough to accept a nominal $300 \mathrm{MW}$ in all possible situations. A heat load chart was adopted on the basis of averaging data for air temperature of the central part of Russia over a ten-year period. This chart is converted into a dependence of total power on the duration of the days of work (Fig. 2). Total power is related to nominal electrical power

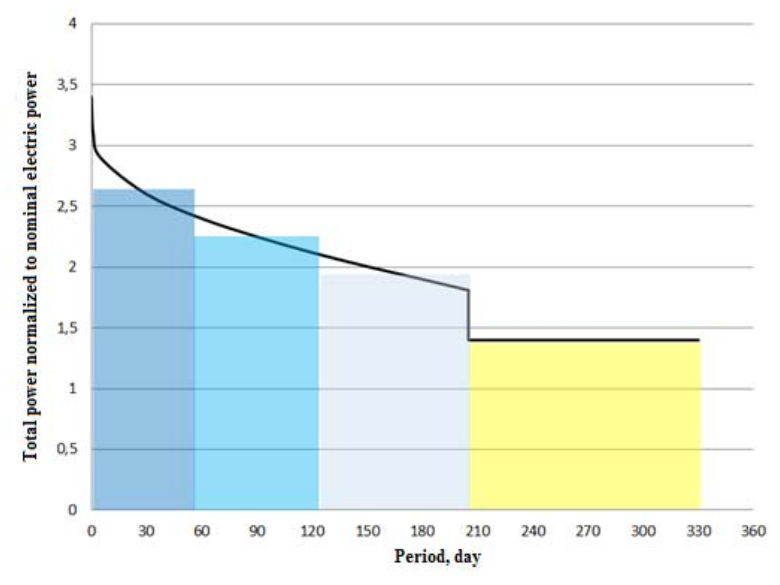

Fig. 2. Adopted annual load schedule.

An area under a line is the energy, generated over the corresponding period of time. The yellow color indicates the energy, generated in the summer, when the heating is not working. During this period of time, with the accepted operational model, approximately a quarter of all annual energy is produced. The heating period can be divided into three equal areas. Such a partition will allow to take into account correctly the change in thermal efficiency with a change in thermal load.

\section{Accepted efficiency criterion for cogeneration of heat and electric energy}

The most indicative criterions for the thermal efficiency of energy facilities work are the integral fuel consumptions during a typical period of time. Heat supply systems operate in annual cycles. Therefore, one year is chosen as a characteristic period of time. It is assumed that there are no other sources of energy than fuel. Thus, in the ideal case, the (minimal) annual fuel consumption will be equal to the ratio of total power (thermal and electric), generated per year, to the higher calorific value of fuel. This fuel consumption is taken as a reference point, and the value, which exceeds it, is taken as a criterion of thermal efficiency.

\section{Description of a calculation model for compressorless CCGT unit}

At this stage of the research, a relatively low level of detail for a calculation was selected, but it was quite sufficient to solve the tasks. All large parts of the installation are considered as "black boxes" the 
operation of which is described by universal characteristics and integral equations. Also, an assumption is accepted that the fuel is pure methane CH4. To take into account the thermodynamic properties of the working fluid, the standard tabular values for the properties of pure components $(\mathrm{CO} 2$, $\mathrm{H} 2 \mathrm{O}, \mathrm{O} 2$, and $\mathrm{CH} 4$ ) were transferred to spreadsheets with an interpolation procedure. Before the combustion process, each component of the working fluid is considered separately as a pure substance. The working fluid is a mixture of gases after the combustion process in the combustion chamber. It is supposed that this is a mechanical mixture of individual gases which do not enter into any chemical reactions between themselves, obeying the Dalton law.

A large group of equipment, being a part of the compressorless CCGT unit, affects the operation of the installation only by means of resistance to a movement of the working fluid. This is taken into account in the general model by the total pressure recovery factor. This group includes gas ducts, pipelines, fittings, nozzles, and etc. In a mathematical model, this equipment is taken into account by the total pressure recovery factors (a ratio of total pressure at outlet to total pressure at inlet of related equipment). As an assumption, it is assumed that the recovery factors of total pressure remain constant by the operating mode changes. Their values for the calculations are given in table 1 .

Table 1

\begin{tabular}{|l|l|}
\hline & Value \\
\hline $\begin{array}{l}\text { Pipelines and fittings for each of the } \\
\text { original components in the area from } \\
\text { the feed pump to the combustion } \\
\text { chamber }\end{array}$ & 0,95 \\
\hline Combustion chamber & 0,9 \\
\hline $\begin{array}{l}\text { All heaters and utilizers for hot and } \\
\text { cold heat transfer fluid }\end{array}$ & 0,95 \\
\hline $\begin{array}{l}\text { Recuperators for cold heat transfer } \\
\text { fluid }\end{array}$ & 0,95 \\
\hline Recuperators for hot heat transfer fluid & 0,97 \\
\hline $\begin{array}{l}\text { Contact condensers for cold heat } \\
\text { transfer fluid }\end{array}$ & 0,9 \\
\hline $\begin{array}{l}\text { Contact condensers for hot heat } \\
\text { transfer fluid }\end{array}$ & 0,97 \\
\hline
\end{tabular}

The pressure increase is carried out by pumping equipment. Theoretically, the required pump power is equal to the product of the volumetric flow rate of the pumped liquid and the pressure difference between the inlet and outlet of the pump. The efficiency of the pressure increase is taken into account the efficiency of the pump. Typical characteristics of centrifugal pumps were used to describe the operation of pumping equipment. A view of used characteristics in relative parameters is shown in Fig. 3.

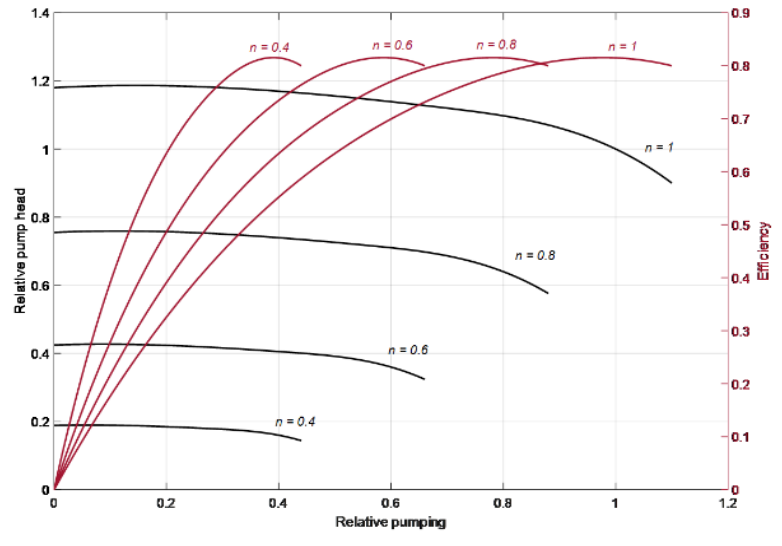

Fig. 3. Typical characteristic of feed pump.

To describe the combined cycle gas turbine, a characteristic in dimensionless coordinates was used, as shown in Fig. 4.

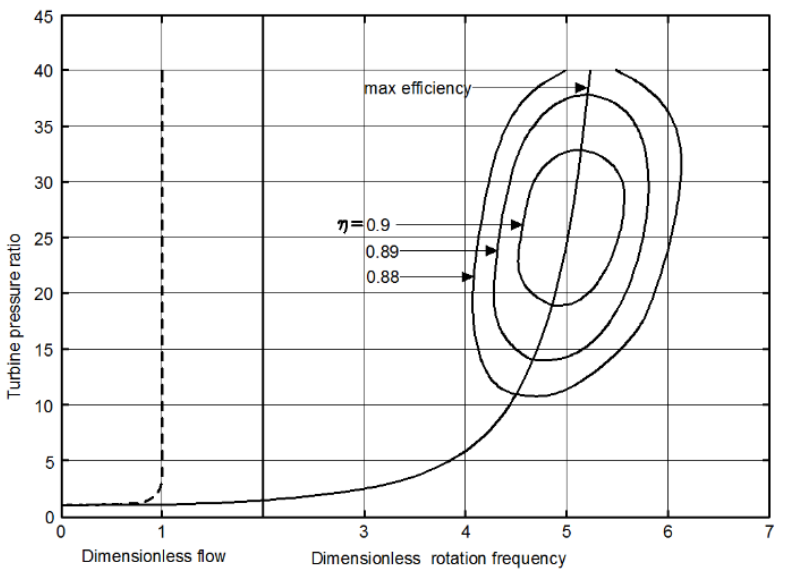

Fig. 4. Characteristic of the combined cycle gas turbine.

The efficiency of heat exchange equipment is taken into account by three factors: thermal efficiency, total pressure recovery factor for a hot heat transfer fluid, and total pressure recovery factor for a cold heat transfer fluid. As an assumption, it is accepted that these coefficients are independent of the installation operating mode. Their values for the calculations are given in table 2 .

Table 2. Value of thermal efficiency.

\begin{tabular}{|l|c|}
\hline Heat exchanger & $\begin{array}{l}\text { Value of thermal } \\
\text { efficiency }\end{array}$ \\
\hline Cold utilizers & 0,95 \\
\hline All heaters & 0,9 \\
\hline Recuperators & 0,9 \\
\hline Contact condensers & 0,95 \\
\hline
\end{tabular}

There are two contact condensers in the scheme of the compressorless CCGT unit in addition to heat exchangers that transfer heat through the wall, separating the heat transfer fluids. In these devices, the heat transfer fluids are not divided. As a result of this, mass transfer processes take place simultaneously with the process of heat transfer. Therefore, the systems of 
equations are supplemented by equations that take into account mass transfer for these devices. Moreover, a number of assumptions were made, the main of which are as follows.

The device has two heat transfer fluids. The heating heat transfer fluid is in the gaseous phase, the cooling heat transfer fluid is in the liquid phase. Part of the heating heat transfer fluid passes from the gaseous to the liquid phase during the cooling process. It is assumed that the liquid phase completely separates from the heating heat transfer fluid in the contact condenser, and it represents dry gas at the outlet. Also, the all liquid phase passes into the cooling heat transfer fluid. It is neglected (not taken into account in the calculation model) that individual components of the heating heat transfer fluid dissolve in the cooling heat transfer fluid.

In addition, it is considered that the phase transition occurs in equilibrium. At the same time, the partial pressure of water vapor fully corresponds to the saturation temperature.

To describe the $\mathrm{CO} 2$ compressor at this stage of research, a compressor characteristic with a thoroughly expanded operating range is conventionally adopted (Fig. 5).

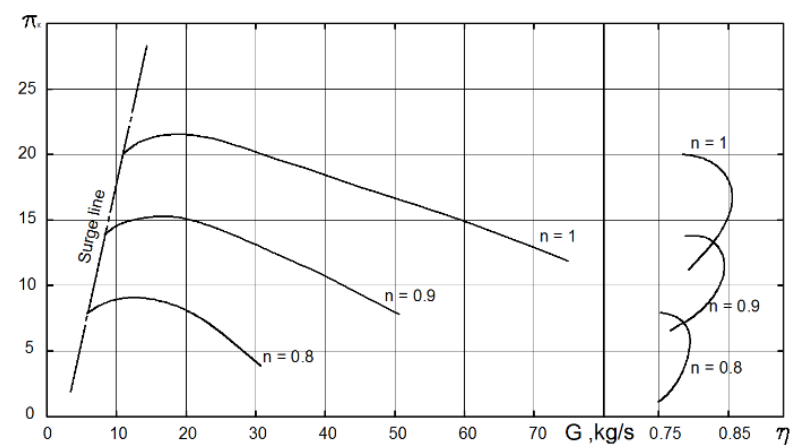

Fig. 5. Compressor characteristic with a thoroughly expanded operating range.

Attention should be paid to the following two parts: a device for producing liquid oxygen - the air separation unit (ASU), and the liquefier for $\mathrm{CO} 2$. Despite the fact that these are rather complex objects, they are considered as "black boxes" in this study. Therefore, the purpose of the research was to determine the required ranges of operating modes of these devices, and not to study the operation of these devices at partial loads.

To obtain liquid oxygen in the quantities, required to ensure the operation of a power plant, the most appropriate technology is cryogenic rectification. The energy, consumed by ASU, is spent mainly on the production of cold. The energy consumption for the production of cold can be determined by the following dependence:

$$
\mathrm{Q}_{\mathrm{e}}=\mathrm{Q}_{\mathrm{c}} \times\left(\mathrm{T}_{\mathrm{h}}-\mathrm{T}_{\mathrm{c}}\right) / \mathrm{T}_{\mathrm{c}} \times(1 / \eta)
$$

where $\mathrm{Q}_{\mathrm{e}}$ - energy consumption; $\mathrm{Q}_{\mathrm{c}}$ - required amount of cold; $\mathrm{T}_{\mathrm{h}}$ - temperature of a hot source (in this case, the environment); $T_{c}$ - required temperature of cold; $\eta$ coefficient taking into account the difference between the real process of obtaining cold and the ideal Carnot cycle.

Considering that the required amount of cold is proportional to the required amount of liquid oxygen, then the power of ASU (NASU) can be determined by the following dependence, taking into account (1):

$$
\mathrm{N}_{\mathrm{ASU}}=\mathrm{G}_{\mathrm{O} 2} \times\left(\mathrm{T}_{\mathrm{h}}-\mathrm{T}_{\mathrm{c}}\right) / \mathrm{T}_{\mathrm{h}} \times\left(1 / \mathrm{E}_{\mathrm{ASU}}\right)
$$

where $\mathrm{G}_{\mathrm{O} 2}$ - required oxygen consumption; $\mathrm{E}_{\mathrm{ASU}}$ coefficient taking into consideration the production efficiency of liquid oxygen.

The temperature, required for the air separation, is the temperature of it liquefaction. The following assumptions are accepted: temperature, required for air separation - $100 \mathrm{~K}$; coefficient, taking into account the production efficiency of liquid oxygen, does not depend on the operating mode of the compressorless CCGT unit. For the performed calculations, a value of the liquid oxygen production efficiency corresponds to $900 \mathrm{~kJ} / \mathrm{kg}$ in standard climatic conditions. Such efficiency of modern air separation units is accepted when installations with oxygen fuel combustion are investigated [1].

A liquefaction of $\mathrm{CO}_{2}$ is also based on a refrigeration cycle. Only in this case, the required temperature is the liquefaction temperature of $\mathrm{CO}_{2}$. The power $\mathrm{N}_{1 \mathrm{CO} 2}$, spent on liquefying, can be expressed by analogy with (2):

$$
\mathrm{N}_{\mathrm{lCO} 2}=\mathrm{G}_{\mathrm{CO} 2} \times\left(\mathrm{T}_{\mathrm{h}}-\mathrm{T}_{\mathrm{c}}\right) / \mathrm{T}_{\mathrm{c}} \times\left(1 / \mathrm{E}_{\mathrm{lCO} 2}\right)
$$

where $\mathrm{G}_{\mathrm{CO} 2}$ - consumption of $\mathrm{CO}_{2} ; \mathrm{E}_{\mathrm{lCO} 2}$ - coefficient taking into account the efficiency of the refrigeration unit.

The nominal mode is selected as follows: nominal external conditions in accordance with ISO standard; nominal power for the electric supply to the grid was adopted equal to $300 \mathrm{MW}$; rated capacity for output of heat energy was taken to be equal to $120 \mathrm{MW}$; maximum power for heat energy output was accepted to be equal to $600 \mathrm{MW}$; the nominal temperature of the working fluid before the turbine was adopted relatively moderate $(1373 \mathrm{~K})$; the nominal pressure of the working fluid before the turbine was taken to be equal to $20 \mathrm{MPa}$; the expansion ratio of the turbine was accepted equal to 30 (it is kept constant in all modes).

The investigated scheme of the power plant has many degrees of freedom for independent control of parameters. It is necessary to choose the laws of regulation so that the problem has a unique solution (the number of degrees of freedom and the number of regulated parameters coincide). It is possible to independently control the speed of all pumps and the compressor for $\mathrm{CO}_{2}$. In addition, there is an opportunity to partially bypass the recuperator of $\mathrm{H}_{2} \mathrm{O}$.

At this stage of research, it is not the purpose to find the optimal laws of regulation, because these laws are highly dependent on the engineering solutions, adopted at the later stages of the creation of the compressorless CCGT unit. One of the possible control laws was adopted for the certainty of calculations (without any claims for the best variant). It is assumed that the regulation of the parameters is as follows: 
- the network water pump regulates the consumption of water proportional to the square root of power, output to the heating network;

- circulation pumps maintain the ratio of water equivalents for hot and cold heat transfer fluids as close as possible to one;

- the $\mathrm{CO}_{2}$ compressor keeps constant an expansion ratio of the working fluid in the combined cycle gas turbine at all investigated operating modes;

- the fuel pump regulates the fuel supply so that to provide a predetermined power supply to the grid;

- the $\mathrm{CO}_{2}$ feed pump maintains a constant temperature of the working fluid at the combined cycle gas turbine inlet at all investigated operating modes;

- the oxygen pump regulates the supply of oxygen so as to provide the minimum necessary excess of oxygen;

- the $\mathrm{H}_{2} \mathrm{O}$ feed pump controls the water supply in such a way as to provide the set power for heat supply to the grid;

If the $\mathrm{CO}_{2} / \mathrm{H}_{2} \mathrm{O}$ ratio has reached its minimum value, the law of thermal power regulation changes. In this case, keeping the minimum value of $\mathrm{CO}_{2} / \mathrm{H}_{2} \mathrm{O}$, a part of the water is bypassed the $\mathrm{H} 2 \mathrm{O}$ recuperator, going directly into the combustion chamber.

\section{Obtained results and their analysis}

In accordance with the adopted laws of regulation, calculations were performed that fully cover the power range for electric supply from 120 to $360 \mathrm{MW}$ (For gas turbine units are required to allow exceeding the nominal power by $20 \%$ unless the parameters, limiting efficiency or resource of an installation, are not exceeded.) and heat supply from 120 to $600 \mathrm{MW}$. The dependence of the efficiency of electric supply on the operating mode is shown in Fig. 6. The dependence of the coefficient of fuel utilization (CFU) on the operating mode is presented in Fig. 7. The above dependencies take into account the energy consumption for own needs.

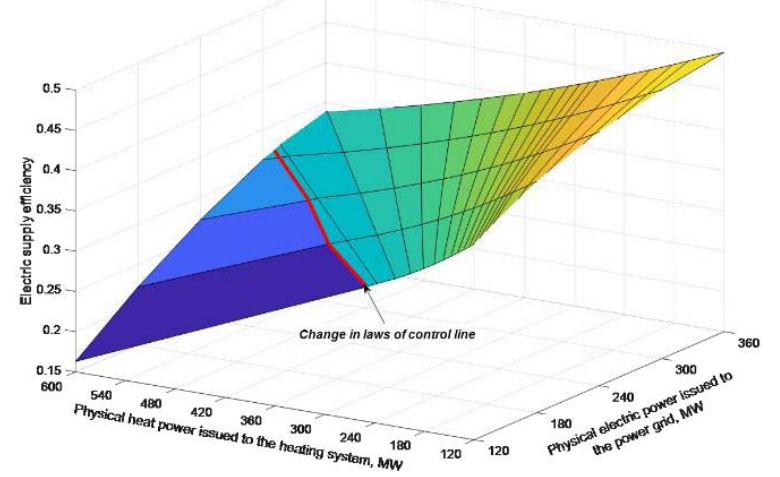

Fig. 6. Dependence of the electric supply efficiency on the operating mode.

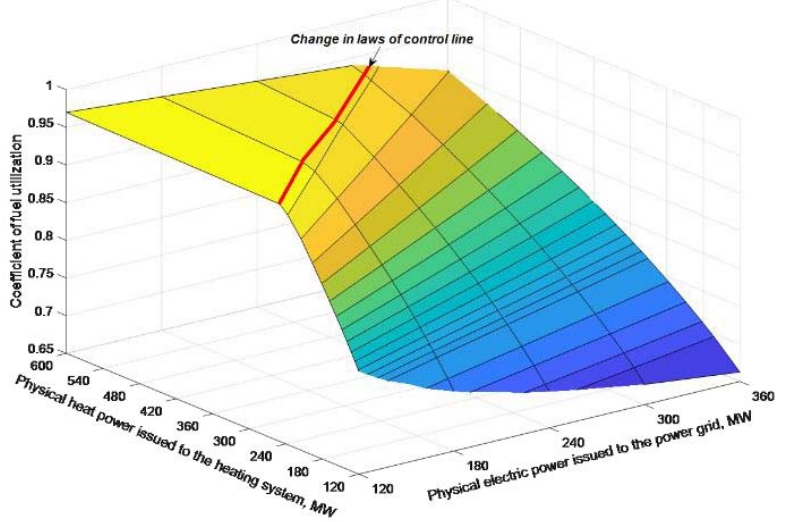

Fig. 7. Dependence of CFU on the operating mode.

It should be noted that the given efficiency and CFU are related to the higher calorific value of the fuel. Natural gas has the higher calorific value approximately $11 \%$ more than the lower calorific value. Therefore, this must be taken into account in a comparative analysis with installations in which these indicators are referred to the lower calorific value. Consequently, with minimal heat production (Fig. 6), the efficiency values, achieved in the compressorless CCGT units, for the electric supply at nominal and at maximum operating modes are equal to $46.9 \%$ and $48.8 \%$, respectively. These values are very close to the level, having achieved by the best combined cycle plants.

Naturally, with an increase in the heat load, the electric supply efficiency decreases. In addition, at high heat loads, when the heat power is five times higher than the electric power, the efficiency can drop to almost 15\% (Fig. 6). Nevertheless, CFU grows (Fig. 7), and it exceeds $95 \%$ at high thermal loads. If this value is reduced to the lower calorific value of the fuel, it will exceed $100 \%$. Such high values of CFU are a consequence of the fact that almost all of the water vapor, included into the working fluid, condenses at pressures, corresponding to higher saturation temperatures than the temperature of the return network water.

Therefore, almost all heat of the spent working fluid, including the vaporization heat of water vapor, resulting from the combustion of fuel, is converted into useful heat. In addition, a large amount of heat with the low temperature is utilized in the basic cycle (the liquid components of the working fluid are heated). As a result, only a part of energy, spent for own needs, is lost which cannot be converted into useful heat. The regulation of thermal power is carried out by changing the ratio of consumptions of recirculating $\mathrm{CO} 2$ and $\mathrm{H} 2 \mathrm{O}$. The effect of such regulation is associated with the redistribution of heat, removed from the cycle. To illustrate this redistribution, the process of heat removal from the thermodynamic cycle in $\mathrm{T}-\mathrm{S}$ coordinates is shown in Fig. 8. 

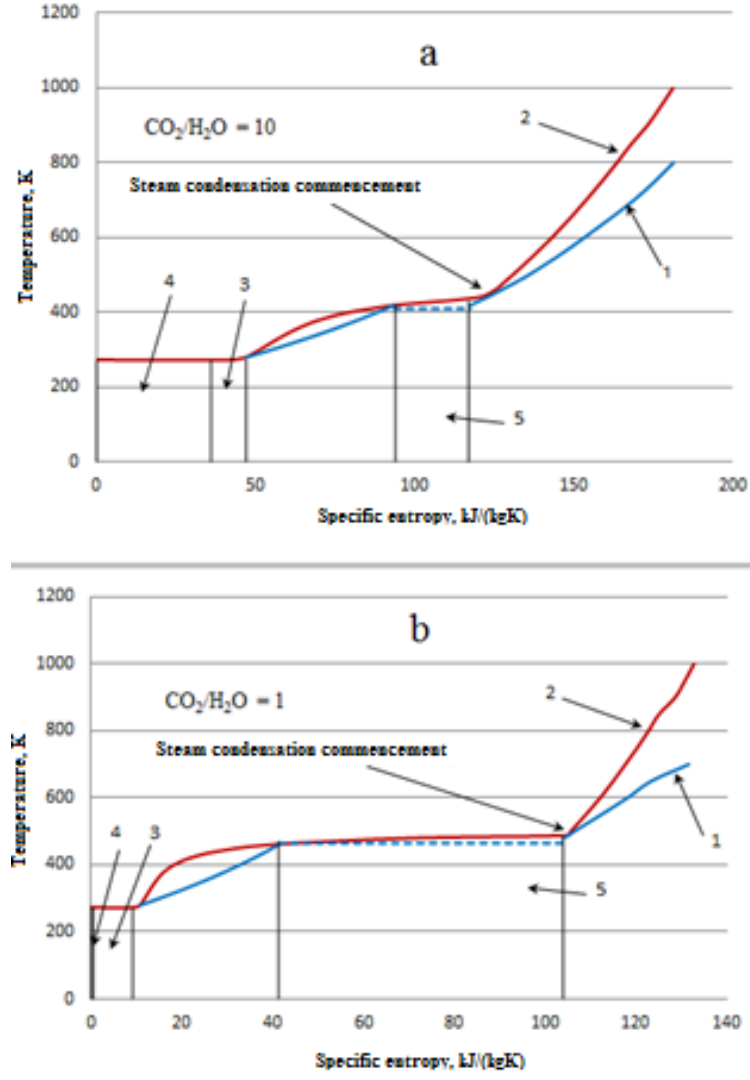

Fig. 8. The cooling process of the spent working fluid in T-S coordinates: 1 - line for heating the components of the working fluid before feeding into the combustion chamber; 2 - line for cooling of the spent working fluid; 3 - heat for warming up fuel and oxygen to the temperature of $\mathrm{CO} 2$ condensation; 4 - heat, removed into the environment; 5 heat, delivered to the heating system.

Entropies S are given in specific units, but all entropies are assigned to one kilogram of fuel for better comparison. The reference points for heating and heated flows are selected so that the minimum temperature head, required to heat transfer, is provided everywhere. If at some point the heat is removed from the cycle, the reference points are adjusted accordingly.

Part of the heat of liquefied $\mathrm{CO} 2$ is distributed to fuel and oxygen heating up to the temperature of $\mathrm{CO} 2$ condensation (area 3). The rest of the $\mathrm{CO} 2$ condensation heat is removed by a refrigeration machine to the environment (area 4). This is the only irrevocably lost fraction of the energy during cooling of the spent working fluid. Part of the heat, removed from the cycle, is sent to the heating system (area 5). The possibility of heat removal to the heating system is connected with the fact that the water equivalent sharply increases at the beginning of water vapor condensation, and part of the heat can be removed from the cycle with a temperature close to the condensation onset temperature of $\mathrm{H} 2 \mathrm{O}$ without prejudice to heat recovery in the cycle.

The onset temperature of $\mathrm{H} 2 \mathrm{O}$ condensation is higher than $400 \mathrm{~K}$ even with the ratio $\mathrm{CO} 2 / \mathrm{H} 2 \mathrm{O}=10$. This heat temperature satisfies the requirements of many heating systems even in the coldest time. The partial pressure of $\mathrm{H} 2 \mathrm{O}$ in the spent working fluid increases with a decrease in the $\mathrm{CO} 2 / \mathrm{H} 2 \mathrm{O}$ ratio, and, accordingly, the onset temperature of $\mathrm{H} 2 \mathrm{O}$ condensation rises. The amount of $\mathrm{CO} 2$ decreases. Hence, the amount of heat, removed by the refrigeration machine, declines and the heat removal to the heating system increases.

Already at a ratio of $\mathrm{CO} 2 / \mathrm{H} 2 \mathrm{O}=1$, the heat removal to the environment approaches zero (Fig. 8b). Thus, almost all fuel energy (at the higher calorific value) is useful. Only a part of the energy, spent on the station own needs, and irretrievable losses during mechanical and electrical energy conversions are lost. The amount of energy loss can be $5-10 \%$ of the electric power of the station. At the same time, all theoretically possible heat is recovered and the temperature level of the network water, which is typical for the coldest days, is provided. The structure of energy losses for compressorless CCGT unit depending on the heat load is shown in Fig. 9.

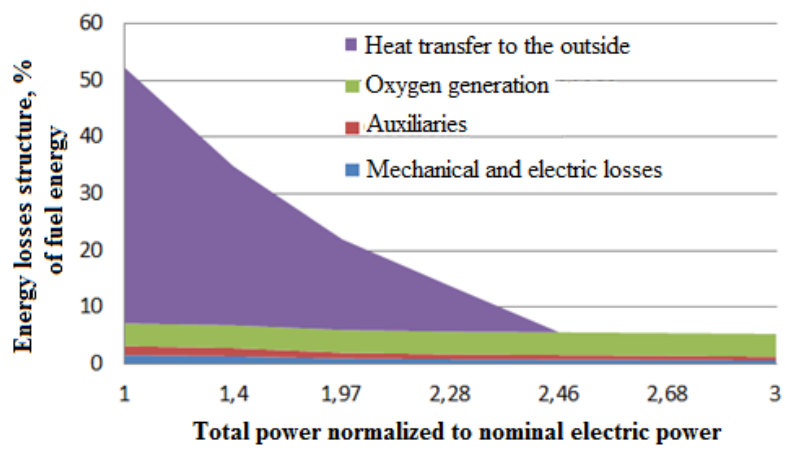

Fig. 9. The structure of energy losses for compressorless CCGT unit.

Energy losses are attributed to fuel energy, determined by the higher calorific value.

Using the dependence of energy losses on the total relative power (the sum of the electric and thermal power referred to the nominal electric power) and the annual load schedule, it is easy to obtain the excessive fuel consumption in the allocated time periods and the total annual excess fuel flow. A bar graph, showing the structure and the magnitude of annual excessive fuel consumption, is presented in Fig. 10.

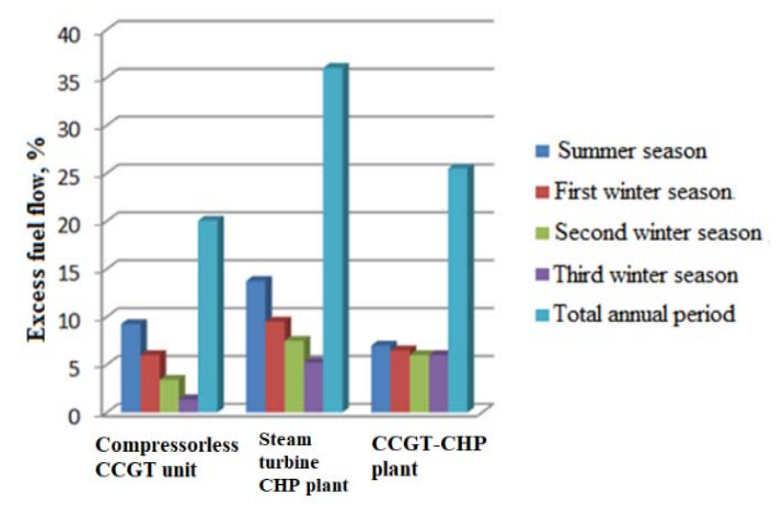

Fig. 10. Structure and magnitude of annual excess fuel flow. 
The highest excessive fuel consumption is occurred in the summer when the heat load is minimal. In addition, the more thermal load is observed, the less excess fuel flow will be. The total annual excessive fuel consumption is slightly less than $20 \%$. This value is a fairly good indicator. It can be illustrated by comparison with alternatives. Two of the most effective technologies for cogeneration of heat and electricity are considered for comparison. Several assumptions are made for the correct comparison.

It is assumed that the adopted operational model of the system in each compared variants refers to the rated power of the corresponding installation. The amount of excess fuel flow refers to the theoretically possible annual fuel consumption. It is expected that all compared options have a possibility to maintain a constant electrical load.

The first technology for comparison is the cogeneration steam-turbine plant T-250/300-240. It is currently the most common unit, belonging to the heating combined heat power plants. This plant is used for cogeneration of electricity and heat for the needs of district heating. In condensation mode, this installation has a specific operating fuel consumption of 326 goe $/ \mathrm{kW}^{*} \mathrm{~h}$. This corresponds to an efficiency of $37.7 \%$, if it attributes to the lower calorific value of fuel, and $33.9 \%$, if it relates to the higher calorific value.

Consequently, the excess fuel flow in this mode is equal to $64.1 \%$. Part of this excess is associated with mechanical and electrical losses in the equipment. Another part is connected with the power consumption for own requirements. These losses can be accepted by a constant share of electric power. Additional part of the excessive fuel consumption is related to water vapour, generated during the fuel combustion, which is emitted along with the exhaust gases of the boilers. This value is about $11 \%$ of fuel energy.

Supplementary part is the heat of exhaust gases, less the heat of water vapour (The condensation heat of water vapour is artificially moved into a separate component to emphasize the difference between the higher and lower calorific values of the fuel.). When the possibilities of increasing the heat capacity due to the regulation of steam extraction have been depleted, peak boilers are switched on. The exhaust gases heat of the peak boilers is another component of the excessive consumption of fuel. But the largest part of the excess fuel flow in the condensation mode is associated with the removal of heat into the condenser.

In the production of heat, steam extraction is produced and, thus, the heat, removed to the condenser, is transferred to the heating system. Thermal capacity is controlled by steam extraction until all steam is redirected to the heating system. In the real case, it is not possible to redirect all steam to heat production, but these small heat losses can be neglected. The structure of energy losses for a steam turbine CHP plant, depending on the heat load, is shown in Fig. 11.

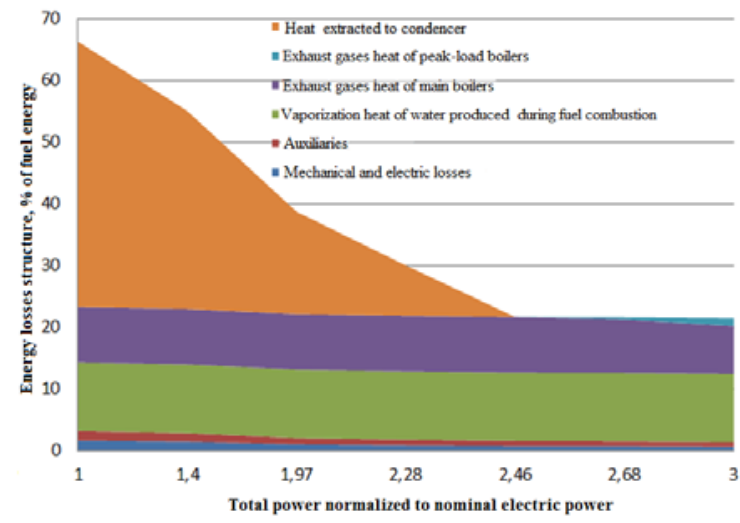

Fig. 11. The structure of energy losses for the steam turbine CHP plant

The total energy losses of the steam turbine CHP plant in the entire range of heat loads are greater than in the compressorless CCGT unit approximately by $15 \%$. The structure and value of the annual excess fuel flow, shown in Fig. 10, show that the steam turbine CHP plant at all time intervals is inferior to the compressorless CCGT unit, and the total annual value of the excessive fuel consumption exceeds more than $15 \%$.

The second technology, adopted for comparison, is a CCGT-CHP plant with cogeneration steam turbines [8]. The initial data for comparison are the following results of thermal tests [8]: efficiency in the condensation mode, referred to the lower calorific value, is equal to $59.8 \%$ (this value corresponds to $53.7 \%$ for the higher calorific value); guaranteed thermal power in the cogeneration mode is $40 \%$ of electric power; $\mathrm{CFU}$ in the cogeneration mode equals $80 \%$ and $72 \%$, respectively, attributed to the lower and higher calorific values. Based on these data, as well as for the steam turbine CHP plant, the dependence of the energy losses structure on the heat load is plotted (Fig. 12).

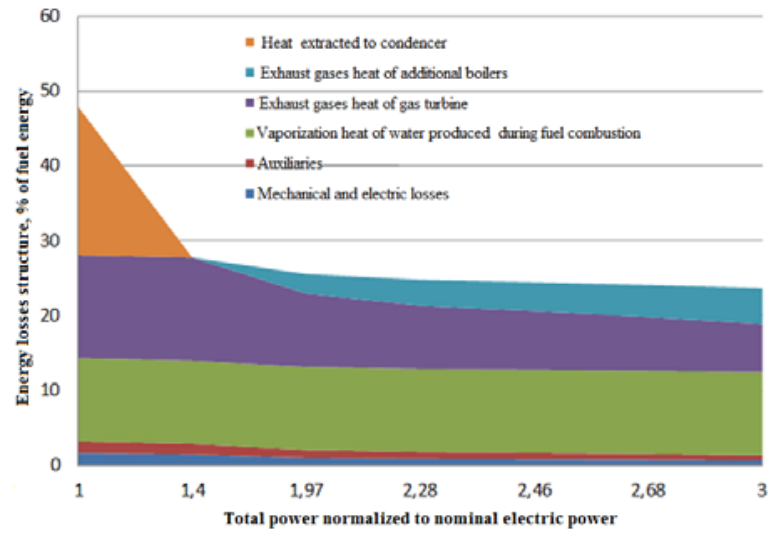

Fig. 12. Energy loss structure of the CCGT-CHP plant with cogeneration steam turbines.

In contrast to STP, heat removal to the condenser is significantly less in the CCGT-CHP plant with cogeneration steam turbines. Consequently, opportunity for heat production is also less. For the adopted operational model of the heat supply system, 
the heat, generated by the CCGT unit, is sufficient only for hot heating. Additional boilers will be required for heating in winter. It is required 2-3 times more exhaust gases per unit of fuel in the CCGT unit than in STP. In addition, the factors are the same that determine the temperature at the exhaust.

Thus, the component of the excess fuel flow, associated with the exhaust gases in the CCGT unit, is also 2-3 times more. These differences lead to a change in the nature of the structure of annual excessive fuel consumption. The excess fuel flow is approximately the same in all selected time ranges (Fig. 10). In the summer period, the CCGT-CHP plant defeats the compressorless CCGT unit about $5 \%$. However, the CCGT-CHP plant is inferior in all other time periods and loses a little more than $5 \%$ in general for the annual period.

\section{Conclusions}

A mathematical model for the compressorless CCGT unit has been developed. It allows to study thermal characteristics in a wide range of operating modes at the earliest design stages. Researches have shown that the cycle of compressorless CCGT unit permits to achieve very high rates of thermal efficiency. The efficiency for electricity supply at the nominal mode can reach $46.9 \%$ even with a relatively moderate temperature of the working fluid before the turbine (1373 K). In addition, CFU exceeds 95\% at high heat loads (referred to the higher calorific value of the fuel).

The obtained design characteristics of the compressorless CCGT unit were used to analyze the thermal efficiency of cogeneration of electricity and heat in district heating systems. The analysis of the efficiency of the compressorless CCGT unit in district heating systems showed their high potential for possible use in such systems. The annual excess fuel flow (exceeding the minimum theoretically possible) is less than $20 \%$ with the adopted operational model of the district heating system, while this value reaches $25 \%$ for the best CCGT units, and more than $35 \%$ for the steam turbine plants.

The high thermal efficiency of the compressorless CCGT unit is achieved by the rational configuration of the heat recovery and utilization system that allows to use all spent working fluid heat, including the heat of water condensation, generated during combustion.

Even without considering the fact that the thermal efficiency of the compressorless CCGT unit is adopted with all the energy costs for removing pure $\mathrm{CO} 2$ from the cycle in the liquid phase state (the most convenient for transportation), there is a significant advantage over the traditional steam turbine plants and CCGT units on this indicator, in which $\mathrm{CO} 2$ is emitted into the atmosphere along with a number of harmful substances in flue gases.
The research was financially supported by the Russian Science Foundation (project № 19-19-00558).

\section{References}

1. Sanz W., Jericha H., Luckel F., Heitmeir F. A further step towards a Graz cycle power plant for CO2 capture //ASME Paper GT2005-68456, ASME Turbo Expo. 2005.

2. Oxy-fuel gas turbine, gas generator and reheat combustor technology development and demonstration / R. Anderson, F. Viteri, R. Hollis et. al. //ASME Paper GT2010- 23001, ASME Turbo Expo. 2010.

3. Yang H. J., Kang D.W., Ahn J.H., Kim T.S. Evaluation of design performance of the semiclosed oxy-fuel combustion combined cycle //Journal of Engineering for Gas Turbines and Power. 2012. Vol. 134. No 11. P. 111702.

4. High efficiency and low cost of electricity generation from fossil fuels while eliminating atmospheric emissions, including carbon dioxide / R.J. Allam, M.R. Palmer, G.W. Brown et. al. // Energy Procedia. 2013. Vol. 37. P. 1135- 1149.

5. Kosoi A.S., Popel O.S., Sinkevich M.V. METHOD AND PLANT FOR MECHANICAL AND THERMAL ENERGY GENERATION// Patent RU 2651918 C1: 24.04.2018 Bull. № 12. http://www1.fips.ru/wps/PA_FipsPub/res/BULLE TIN/IZPM/2018/04/27/INDEX_RU.HTM

6. A.S. Kosoj, A.A. Kosoj, M.V. Sinkevich, Y.A. Antipov METHOD AND PLANT FOR MECHANICAL AND THERMAL ENERGY GENERATION // Patent RU 2665794 C1: 04.09.2018 Bull. № 25.

7. The Conceptual Process Arrangement of a SteamGas Power Plant with Fully Capturing Carbon Dioxide from Combustion Products / A. S. Kosoi, Yu. A. Zeigarnik, O. S. Popel, M. V. Sinkevich, S. P. Filippov, V. Ya. Shterenberg // Thermal Engineering, 2018, Vol. 65, No. 9, pp. 597-605. DOI: $10.1134 / \mathrm{S} 0040601518090045$ A. S. Kosoi, Yu. A. Zeigarnik, O. S. Popel et. al., Thermal Engineering, 65(9), 597-605 (2018)

8. Эксплуатационные характеристики теплофикационной парогазовой установки мощностью 420 МВт [Текст] / Ольховский Г. Г. [и др.] // Электрические станции. - 2014. - № 1. - С. 14-20 : 7 рис. - Библиогр.: с. 20 (2 назв. ) . ISSN 0201-4564

\section{Acknowledgment}

